\title{
EL TEATRO ESPAÑOL EN LA TRANSICIÓN: ¿UNA GENERACIÓN OLVIDADA?
}

Mariano DE PACO

Universidad de Murcia

A la memoria de Alberto Miralles,

que tanto luchó desde el teatro por defenderla.

«El tiempo es olvido y es memoria» es una afirmación de Borges que Fernán Gómez sitúa al comienzo de una Autobiografia («El olvido y la memoria»), escrita en marzo de 1987 y luego al frente de su Puro teatro y algo más (2002). En uno de los artículos de este libro recuerda, por cierto, que «es una costumbre actual muy extendida -sobre todo en el mundo del arte, de la cultura, de la diversión-volverse de espaldas al pasado inmediato». Al olvido natural propiciado por el tiempo se añade esa «costumbre». En el caso al que en este trabajo nos referimos hubo motivos que determinaron ( $y$, de rechazo, determinan aún) la pérdida de memoria. Cuando, por otra parte, se intenta paradójicamente recuperar hechos de ese pasado (Romera, 2003), ¿hay una mera voluntad melancólico-nostálgica, como en una serie de éxito que Televisión Española tiene en antena? ¿Hay un loable afán de estudio y análisis que, sin embargo, no puede aportar soluciones? ¿Hay un deseo de aprovechar una moda de pingües resultados? No es, desde luego, una recuperación con sentido crítico en la que el pasado sirva para «iluminar» el presente, tal como Buero Vallejo concebía el teatro histórico y como lo escribieron Sastre, los realistas y los autores del nuevo teatro (De Paco, 1999). Todos ellos están incluidos en un amplio grupo que excede con mucho el término generación que figura en el título de este trabajo y que, no obstante, creo que sirve para entender de quiénes hablo puesto que lo más importante es el tiempo histórico al que nos referimos. 
No es el objeto de mi exposición hacer un panorama del teatro en la España democrática: ya se han realizado apreciables trabajos sobre ello, como el temprano de Luciano García Lorenzo (1978-1980), o los de Fernández Torres (1988) y de Manuel Aznar (1996). Tampoco me propongo detallar logros y menguas de la escena en la transición'. Deseo simplemente mostrar de modo sucinto la situación general de desatención (con nefastas consecuencias) hacia los dramaturgos españoles vivos en los primeros años tras la muerte de Franco y poner unos ejemplos significativos de autores de distinta edad y actitud creadora.

Por no eludir una cierta precisión temporal señalo que mi término ad quem, es decir, la nueva generación que linda con la que ahora considero podría resumirse en los nombres de José Luis Alonso de Santos, que en 1981 estrena La estanquera de Vallecas y obtiene un gran éxito con Bajarse al moro (1985); de Fermín Cabal, que en 1982 estrena Vade retro! y un año después Esta noche gran velada; o de Ignacio Amestoy, que escribe en 1979 Mañana, aquí, a la misma hora.

\section{Las «operaciones» de recuperación y el «pacto de silencio»}

En 1982 publicó Francisco Ruiz Ramón un conocido artículo en el que hacía un «Balance del teatro español en la España post-Franco», en el que se refirió, con expresiones de unos años antes que hicieron fortuna, a la operación rescate de «grandes textos dramáticos españoles de aquellos autores anteriores a la guerra civil cuya herencia estaba públicamente sin repartir, frutos de otro presente que habia quedado interrumpido por la misma guerra civil y, subsiguientemente, por la dictadura franquista», así los estrenos de Valle-Inclán (Los cuernos de don Friolera, Divinas palabras), García Lorca (La casa de Bernarda Alba, Asi que pasen cinco años) y Alberti (El adefesio, Noche de guerra en el Museo del Prado), y a la Operación restitución «de textos prohibidos en el pasado inmediato, casi antepresente, escritos durante la última década del franquismo» (Buero Vallejo, Martín Recuerda, Rodríguez Méndez -éxitos-; Olmo, Nieva, Arrabal, y Matilla -fracasos, según Ruiz Ramón, por inadecuación de los códigos de la propuesta escénica y del texto o por falta de experiencia del público-) $)^{2}$. Habría que añadir el estreno de Retrato de dama con perrito, de Luis Riaza, «bellísimo espectáculo teatral» que entusiasmó a Ruiz Ramón y sobre el que publicó un laudatorio artícu-

Una completa información puede verse en el capítulo dedicado a la escena del trabajo del Equipo Reseña (1989-1991: 143). De interés son también los artículos que al tema se dedican en Amell-García Castañeda (1988: 103-136).

${ }^{2}$ Estas ideas se recogieron después parcialmente en el capítulo X de Ruiz Ramón (1988: 209-221). 
lo en Triunfo (entendido como un cambio respecto a sus nada positivas opiniones sobre el nuevo teatro) y que fue «un fracaso de público» ${ }^{3}$.

Todo hace pensar en la interrelación que cada texto tiene con su contexto, que impide la traslación simple de unas circunstancias a otras. Pero a ello se sumaba que, tanto por la ampliación de criterios de los años postreros de la dictadura (Monleón, 1976: 53), como por las perspectivas ante su inminente fin, se alimentaba una ilusión de grandes logros que resultó incumplida ${ }^{4}$.

La politización del estreno de El adefesio, de Alberti, es una buena muestra de la mediación político-social en la actividad dramática. Como escribió Pedro Altares en la recién nacida Pipirijaina (1976: 43), «la función quedó hecha añicos. Gorgo no es un personaje poético de ficción: es María Casares, exilada e hija de exilados» y el autor es «el gran poeta comunista». En su comentario se mezclan los sucesos del exterior con el espectáculo de dentro. Hubo muchos aplausos pero el teatro Reina Victoria no fue una fiesta sino «el emotivo recuerdo colectivo de 40 años de lucha, y de luchadores de dentro y fuera, por la libertad. Que, como Alberti, aún está ausente...». Y, en la crítica de la misma revista, Carlos Gortari afirmaba que el estreno constituía «un episodio más de la ceremonia de confusión a la que cotidianamente asistimos» porque en él estaban «presentes todas las graves contradicciones de la España de hoy» (1976: 49).

La llegada de la democracia había despertado amplias y esperanzadas expectativas en el ámbito del teatro español, tanto tiempo amordazado por la censura, que ponía trabas al autor para expresarse, al productor para sufragar el espectáculo, al actor para manifestase en libertad y al público para conocer lo que sus artistas querían decirle desde la escena ${ }^{5}$. Pero la esperanza se tornó desencan-

${ }^{3}$ Por su condición, hemos de dejar aparte el caso de Abre el ojo, de Rojas Zorrilla, que para el crítico mostraba uno de los males endémicos del teatro español, «la inexistencia de una auténtica tradición creadora con respecto a nuestros clásicos» (1992: 73).

+ Monlcón escribió: «La previsión parecía razonable: con la democracia debía afirmarse un teatro superior al que tuvimos durante la Dictadura. La práctica confirmaba esta argumentación. Hasta que, súbitamente, la previsión se interrumpió y el teatro entró en barrena. ¿Por qué?» (1977: 56). En el resto de su artículo se propone contestar a esa compleja pregunta.

${ }^{5}$ El Real Decreto 262/1978, de 27 de enero (B.O.E. de 3 de marzo), disponía la «libertad de representación de espectáculos teatrales», comenzaba con esta ansiada afirmación: «La libre expresión del pensamiento a través del teatro y demás espectáculos artísticos, como manifestación de un derecho fundamental de la persona, no puede tener otros límites que los que resulten del ordenamiento penal vigente, así como del respeto debido a los intereses generales». Una Orden del Ministerio de Cultura publicada en el B.O.E. de 14 de abril de 1978, dictó «normas sobre la calificación de espectáculos teatrales». Para estos últimos años de la censura «oficial» es de gran utilidad el estudio de Berta Muñoz Cáliz, La censura teatral durante la dictadura franquista, tesis doctoral defendida en la Universidad de Alcalá de Henares en marzo de 2004; aún inédita, debemos su conocimiento a la amabilidad de la autora. 
to y comenzaron a surgir voces que clamaban por no obtener lo que en justicia consideraban suyo, al tiempo que denunciaban el engaño sufrido (Serrano, 1997: 75-92).

Alberto Miralles denunció, con el mismo vigor con el que se había enfrentado a la dictadura, la situación de la política teatral de estos años de la transición señalando, entre otros aspectos, la oposición de los autores con cierta crítica empeñada en certificar «la defunción de todo el teatro antifranquista» (Serrano, 2004: 9-36). Sin entrar en los detalles de la polémica que se suscitó, recordemos que, en síntesis, oponía las contradictorias opiniones de quienes creían necesarios nuevos autores para una nueva sociedad (haciendo tabla rasa del pasado) y de los que (sobre todo, dramaturgos), aun admitiendo la falta de validez de algunas obras, creían que mucho era salvable y que era necesario atender a esos escritores. La «Encuesta a los que no estrenan» (1978: 49-54), en la que participaron José Arias Velasco, Diego Salvador, Ángel García Pintado, Jerónimo López Mozo, Luis Matilla, Alberto Miralles y Miguel Romero Esteo, es muy elocuente; las respuestas tenían tonos diferentes pero un desaliento común que respondía a la mediocridad de las carteleras, al dominio de los empresarios, al imperio del «destape», y sobre todo, a que el mayor fraude ha sido el de impedir la progresión de los autores al «taponarnos casi todos los caminos posibles», porque hay una «creencia global de que, muerto Franco, los textos han dejado de ser interesantes y actuales».

El punto de vista adverso puede personificarse en el crítico Eduardo Haro Tecglen (miembro además, de la Junta Consultiva del Centro Dramático Nacional), que en unos artículos en Hoja del Lunes «venía certificando la defunción de todo el teatro antifranquista». Ante esto, casi una veintena de autores y críticos publicaron un Manifiesto que denunciaba «el estado comatoso del teatro, aclarando sus causas», la principal de las cuales «era la falta de ayuda al teatro español vivo». El ofensivo artículo de Haro «El manifiesto de las denuncias» (Hoja del Lunes, 29 de enero de 1979) y la respuesta de ellos en «No pasamos por el Haro» (Hoja del Lunes, 5 de febrero de 1979), fueron episodios principales de esta enconada querella.

Una de las actitudes «a favor» mantenida durante más tiempo y manifestada con contundencia mayor fue, como hemos indicado, la de Alberto Miralles, desde su artículo «¿Es la guerra, más madera!» (1979: 12-24), donde se dan todos los detalles de la disputa indicada, hasta la provocativa imprecación: «El nuevo teatro español ha muerto. ¡Mueran sus asesinos!» (1986: 21-24), donde revela las causas de lo ocurrido

"Hasta el fin de su vida siguió escribiendo audaces textos teóricos en los que denunciaba una injusta situación que el tiempo iba cubriendo sin resolver; así, en «La memoria asesinada» (Miralles. 
Los partidos políticos, durante la clandestinidad, habian pedido al teatro crítica, lucidez y desmitificación. Después, en pugna con el poder, querían evitar la provocación a la ultraderecha por miedo a los tanques, y así, el teatro tuvo que perder la agresividad que tanto ayudó a la lucha antifranquista.

Las denuncias de Miralles podrían parecer simple reacción personal de un autor que se sentía ofendido; pero las presiones, ataques interesados y censuras encubiertas se suceden; lo veremos en los casos de Buero y de Domingo Miras. El conjunto de la autoría dramática pierde valor y su desconocimiento aumenta hasta quedar casi reducido a un conglomerado de nombres (Miras, 1983). La desconfianza y la falta de verdadero interés provocaron fracasos que, a su vez, acrecentaron la visión negativa:

El examen de la asignatura pendiente se saldó con un rotundo fracaso que sirvió para llenar de razones a nuestros detractores y para aumentar considerablemente su número. Las pocas obras que se estrenaron en los primeros momentos de la transición no gozaron del apoyo de quienes las programaron. Lo hicieron atendiendo más a un compromiso moral que al deseo real de rescatarlas del silencio que las envolvía. Por eso emplearon pocos medios en los montajes y en su difusión, arrinconaron las representaciones a los días y horarios en que la asistencia de público es menor, pero sobre todo, y esto es lo más grave, demostraron que ni creían en nuestro teatro, ni lo entendían, ni estaban dispuestos a hacer el más mínimo esfuerzo por entenderlo (López Mozo, 1986: 37).

Un editorial de El País («El desierto es el desierto», 22 de abril de 1979) resumía la situación, malévolamente, pero con un trasfondo de verdad, en estas frases:

Los autores no estrenan: los viejos - los antiguos, los de antes- se resignan, pero maldicen; los nuevos, que ya tienen canas y ven con angustia que el tiempo se les pasa, elevan su cólera hacia lo que pueden, y se quedan como estaban. Los grupos independientes siguen una vida áspera y pobre; se siguen sintiendo perseguidos y abandonados.

$\mathrm{Y}$ todos piden dinero.

1998: 99-118) se refiere al pacto de silencio que se impuso tácitamente (valga la paradoja) para salvar la democracia, que beneficiaba sobre todo a los interesados en el olvido, que «se hacia imprescindible porque cualquier pequeña cata en las hemerotecas hubiera sacado a la cegadora luz de los rencores las opiniones más terribles sobre personalidades imprescindibles para llevar a cabo el proceso democrático» (p. 106). También desde la creación, afrontó las mismas cuestiones; en Céfiro agreste de olimpicos embates (1981) lo hace con las que le preocupaban ante el estado del teatro a finales de la década de los setenta («sometimiento» de los grupos, subvenciones, centenarios, olvido del autor actual...). Mucho tiempo después, en El volcán de la pena escupe llanto, Premio Margarita Xirgu de 1997, el protagonista representa una denuncia similar a la que hace Miralles en los artículos teóricos. 


\section{La obra de Buero Vallejo en la transición}

«Un estreno de Buero nunca ha sido cualquier cosa. Mucho menos, cuando Buero estrena en un clima -relativo al menos- de libertades cívicas. La detonación marca un hito más en los dramas históricos de este autor que por sí solo llena toda una época». Estas palabras, con las que iniciaba una entrevista Miguel Bayón (1977: 23) días después del estreno del drama La detonación, resumían distintos aspectos coincidentes en la representación de la primera obra de Antonio Buero Vallejo escrita con posterioridad a la muerte de Franco. Pero entre ellos, junto a un reconocimiento innegable, se filtraba también un injustificado recelo. Las actitudes de la crítica ante la obra de Buero Vallejo en los primeros años de la democracia se manifestaron, en efecto, de un modo irregular.

La doble historia del doctor Valmy, cuyo estreno no se había permitido durante la dictadura, llegó al público el 29 de enero de 1976 con gran éxito. El 20 de septiembre de 1977 se estrena La detonación con un ambiente «enrarecido», del que el propio autor era consciente:

Este era el estreno del «ahora o nunca) pues el Dr. Valmy se había escrito muchos años antes. Esta era mi primera obra posfranquista al 100 por $100, y$ la ocasión de ver si Buero, aun siendo antifranquista, no sabía asumir la nueva (pero no tan nueva) situación y se iba al garete con Franco. De lo contrario, habría que resignarse con un Buero que seguía caminando... ${ }^{7}$

La obra fue muy bien recibida por el público (178 representaciones) y de modo desigual por la crítica. Algunos advirtieron sus valores con ponderación; otros fueron menos equilibrados y llegaron a muy erróneas apreciaciones; en algún caso, además, se cayó en una absoluta mezquindad. Ricard Salvat (1978: 17), que opinaba que «La detonación es, sin duda ninguna, la obra más importante que se ha estrenado en España, de autor español, después del 20 de noviembre de 1975, y la única que apunta hacia una posible dramaturgia del futuro», dejó constancia acertadamente de que la crítica había adoptado ante la obra «una posición muy reticente y un tono que nos resulta extrañamente exasperado», para denunciar la injusta e incomprensible animadversión que hacia Buero mostraban algunos:

Una de las críticas, la que se publicó en la revista Cambio l6 (10-16 octubre 1977) es, a nuestro juicio, prácticamente inaceptable en un país mínimamente desarrollado culturalmente. Esta crítica me sorprendió porque recientemente había estado en Varsovia, donde pude comprobar el respeto y admiración en que se te tiene y donde, como ya sabes, obtiene o ha obtenido un éxito extraor-

\footnotetext{
${ }^{7}$ Carta particular de Buero Vallejo fechada el 14 de octubre de 1977.
} 
dinario El sueño de la razón en la visualización de A. Wajda. Por otro lado sé de la reverencia que por ti se siente en la R.D.A. o en Italia, por citar sólo dos dramáticas que conozco un poco. ¿Cómo es posible un ataque tan personal, ya que nunca se puede considerar crítica lo que allí se publicó, en una revista de la categoría y características políticas de Cambio $16 ?$ ¿Qué razones hacen posible que estas actitudes típicas del franquismo, esos abusos de poder, se sigan repitiendo?

Esas «actitudes» se acentúan en el estreno de la obra siguiente, Jueces en la noche (2 de octubre de 1979): el drama, de gran complejidad técnica, donde criticaba con valentía los males de la sociedad de ese momento, se refería a los «oportunistas» del viejo régimen supervivientes en el nuevo, e incluso advertía de la amenaza de un golpe de estado militar, fue objeto de unas críticas negativas. La empresa, con la excusa del agotamiento de la subvención, "se negó a hacer propaganda» y realizó «una ejecución sumaria» del montaje". La acusación de un crítico que había ejercido de censor $^{10}$ podría resumir el sentido general de la repulsa: Buero posee una gran historia como autor pero «ha sido víctima de la propia actualidad. No ha logrado trascender el tema» (Prego, 1979: 48) ${ }^{11}$. No faltaron quienes salieron en defensa del dramaturgo de un modo general (Martínez Ruiz, 1979: 31) o apuntando de modo certero a la raíz de la cuestión:

Antonio Buero estrena, a los treinta años de iniciar su carrera teatral. Y estrena una obra en la cual, con todos los fallos que se quiera, sigue machacando en el clavo de la denuncia de una sociedad que no puede erigirse en espejo para las generaciones venideras. Pues bien, una parte de la crítica -la de la derecha pero también otra progresista y joven- se está comportando como si Buero sobrase en nuestros escenarios. La crítica de la derecha, de un modo diáfano,

"Salvat se referia a «Abarcar sin apretar», de Eduardo Mallorquí, insidioso texto en el que, entre otras, se hacía esta disparatada sugerencia: «En suma, cabría recomendarle al autor que, si le interesa conservar el prestigio que tan generosamente le ha concedido España, se abstenga en un futuro de estrenar nuevas comedjas» (84).

"Buero Vallejo añadía que «salvo el público, nadie tenía interés en que siguiera», en carta particular fechada el 10 de diciembre de 1979.

${ }^{10}$ «Por ese deseo de borrar la memoria se olvidaron los pasados infames. $Y$ así pudieron los de antes ser los de siempre. Concretamente, ¿fueron los censores aherrojados? No, continuaron exhibiendo sus ominosas patologías en tribunas públicas, mediante la crítica teatral en diarios y emisoras nacionales, dirigiendo festivales, asesorando la cultura en entidades públicas, decidiendo el destino de las ayudas y recibiendo premios y subvenciones...» (Miralles, 1998: 105).

"Un comentario sin firma publicado en el semanal Los domingos de ABC (28 de octubre de 1979,31) tenía como título «A Buero le iba mejor con la censura», para lo que se basaba en la falta de éxito de las «comedias estrenadas del 76 a nuestros días». El dramaturgo respondió en una carta al director ( $A B C, 2$ de noviembre de 1979: 71; reproducida en Buero, 1994, II: 502-504) señalando la falsedad de la noticia y advirtiendo de que «mucho prospera hoy, contra mí o contra otros escritores, la especie de que, con la libertad, no atinamos». 
acusando de revanchista a un discurso en el que se pide el olvido de la guerra. civil que mancha a quienes la hicieron-, pero iluminar los años que la siguen y el hoy resultante. Se trata de una actitud comprensible porque quienes hablan así continúan instalados en el Poder y aspiran a seguir dando gato por liebre. Lo que ya no veo tan comprensible es la pretensión más o menos expresa -o, cuando menos, el tono que permite deducir aquélla- de quienes piden a Buero que se aparte para cederle el sitio a otras voces renovadores.

Que el teatro español necesita no renovarse, sino resucitar, es algo obvio. Pero que esta resurrección haya de pasar por el alejamiento de una figura como la de Buero constituye, a mi parecer, otro error igualmente obvio (Montero, 1979:27).

\section{«Lo que va de ayer a hoy...»}

Cuando Domingo Miras recibió el Premio Lope de Vega (1975) por De San Pascual a San Gil, hubo de esperar el estreno (previsto en la convocatoria) en el Teatro Español de Madrid hasta 1980, después de haberse representado un año antes en el Real Coliseo de San Lorenzo del Escorial por la compañía privada El Búho $^{12}$. La valoración de la obra sufrió las consecuencias del cambio político de la dictadura a la democracia coronada, y se creyó inaceptable lo que cinco años antes había sido galardonado y apreciado. La dramatización de unos sucesos del reinado de «la reina castiza» y de su «corte de los milagros» no parecía oportuna cuando la casa de Borbón acababa de volver a ocupar el trono de España (Serrano, 1991: 117-119).

En la crítica de la representación de El Escorial, Pérez Coterillo (1979: 46) se refería a las dificultades habidas para el montaje e indicaba:

«Por qué es tan absurdamente dificil hacer teatro en España?», se preguntan en la primera página de su programa las gentes de El Búho. La contestación es bien sencilla. A pesar del cambio político, a pesar de la Constitución, a pesar del Parlamento, a pesar de los propios partidos políticos, nada ha cambiado en la práctica en los hábitos teatrales del franquismo. A la desaparición de la censura administrativa han sucedido formas sutiles de pervivencia censorial...

Tras el estreno en Madrid, Haro Tecglen considera al dramaturgo «una víctima de las consecuencias de la España que denuncia» y «comprende la desorientación del autor hasta su intención -declarada- de abandonar el oficio». Porque la obra «llega a su estreno en el Español fatigada, usada. [... Parte de la respon-

${ }^{12}$ El Teatro Español había sufrido un incendio, pero quienes tenían el compromiso de estrenar no se preocuparon de cumplirlo, por más que el Ayuntamiento contaba «con un nuevo espacio teatral, el Centro Cultural de la Villa de Madrid, dedicado a una programación teatral imprevisible y en su mayor parte descabellada) (Pérez Coterillo, 1979: 46). 
sabilidad de todo esto está en unas supuestas autoridades teatrales que impidieron el estreno de la obra en su momento y en condiciones óptimas y terminan ahora liquidándola de un bajonazo» (1980: 37).

Si algunas críticas apuntan a la responsabilidad política de quienes gobiernan la escena, otras dejan ver la de los propios columnistas, dirigidos por sus prejuicíos o compromisos. Así, López Sancho (1980:49) lanza desde el monárquico $A B C$ un enfurecido ataque que comienza con muy malos modos («Algún gitano está cuidando el nuevo destino del Teatro Español...»), continúa desautorizando a quienes le dieron el premio a una obra que «no es de recibo» y concluía que «así no se renueva el teatro nacional». Estaba muy claro que le molestaba que hubiese subido a la escena este «episodio oscurantista de un reinado en el que hubo muchas cosas positivas».

Pero la crítica que entra en lo esperpéntico y cae en el «chafarrinón» que denuncia en el texto, es la de Antonio Valencia (1980: 5), que, siendo miembro del Jurado que la premió, no encuentra ahora el modo de justificarlo:

Conocí «an ovo» [sic] o poco menos De San Pascual a San Gil porque formé parte del jurado que la [sic] dio a esta obra de Domingo Miras el Lope de Vega. Lo menos que puedo decir es que no la reconocí al cabo del quinquenio. ¿La ha engrosado el autor, haciendo uso de la libertad de expresión que va de ayer a hoy, o la ha desnaturalizado la incorporación y versión escénica de Gerardo Malla, que es grosera, burda y desdichada? No to sabemos ni excluimos el error que no queremos agravar con la contumacia y mantenerla y no enmendarla. Lo cierto es que lo que creíamos que era un esperpento farsesco, sacado un poco de La reina castiza y más de clima de El nuedo ibérico valleinclanesco se nos ha convertido en un chafarrinón o una serie de chafarrinones sin gracia.

El sinsentido de estas palabras refleja quizá el que constituyó la situación del teatro en estos años, de la que hubo sin duda más de una «víctima».

\section{Ataques y desencanto}

Los años finales de los sesenta y la década siguiente constituyen una época particularmente dificultosa en la vida de Alfonso Sastre y en su relación con el teatro (De Paco: 1996). En 1967 tiene lugar el estreno de Oficio de tinieblas y no se produce otro en un teatro comercial hasta el de La taberna fantástica, en septiembre de 1985. Sin embargo, el mencionado grupo El Búho ${ }^{1.3}$ es autorizado

${ }^{13}$ El colectivo El Bủho (dirigido por Gerardo Malla, que protagonizó esta obra y fue actor en De San Pascual a San Gil), respondía a un voluntarioso empeño privado que no contaba con los medios que estas obras precisaban. Xavier Fábregas (1977: 64) afirmaba en su crítica: «El Búho, al emprender el montaje de La sangre y la ceniza, ha llevado a término una empresa que era superior a sus fuerzas...». 
en 1976 a montar La sangre y la ceniza, cuya edición no se permitió en el primer volumen de Obras Completas (que no tuvieron continuación) y había sido prohibida por la censura cinco años atrás. Parecía, pues, que, al menos en la escena, se advertía la presencia, «el regreso forzoso», de Alfonso Sastre.

Durante una representación en la Sala Villarroel de Barcelona hizo explosión una bomba colocada por la «Triple A»; la revista Pipirijaina (que editó esa obra en Pipirijaina Textos 1) dedica al autor unas páginas de su número 4 bajo el título «Alfonso Sastre, en ninguna parte», y él publica en El País su artículo «¿Dónde estoy?», en el que se afirma del mismo modo, «en ninguna parte» (Sastre, 1994) ${ }^{14}$. En las anotaciones de ¿Dónde estás, Ulalume, dónde estás? (1990) manifiesta de modo terminante, por todo ello, su voluntad de dar por acabada su escritura teatral, decisión que es preciso relacionar con lo antes indicado y con el descontento o la amargura de muchos de nuestros más valiosos dramaturgos que habían escrito durante la dictadura. Si la insatisfacción se manifiesta a veces posteriormente, tiene su origen en la situación de «abandono» en la que se encuentran en una sociedad que ha decidido, al cambiar, no tenerlos en cuenta, a pesar de algunos montajes esporádicos y sin convicción:

Muerto Franco, la mayoria de los españoles quiso que también muriera con él ese periodo histórico, aunque le asustara no saber con certeza cuál podría ser el que viniera a sustituirlo. Con todo, estaba claro que la democracia era el sistema menos alarmante, pese a las obvias dificultades que habría que superar para conseguirlo. [...] Primero había que borrar el franquismo de la memoria, aunque eso supusiera borrar también el antifranquismo. La Amnistía fue más amplia de lo que parece. No sólo permitió que salieran de la cárcel las víctimas, sino que impidió que entraran sus verdugos (Miralles, 1998: 100 y 106).

Bástennos unas reveladoras muestras sacadas de unos escritos de la sección teatral de una revista universitaria. José María Rodríguez Méndez (1988) confesaba: «Al cabo de tantos años, me siento un desconocido, especialmente en mi país, para el que escribí toda mi obra». Algo después José Martín Recuerda (1990) dejaba ver sus quejas: «Y ahora [...] todo me parece peor, que ya es decir», y Lauro Olmo (1990) su perplejidad: «No tiene explicación el que hoy, precisamente hoy, un autor de mis características pueda sentirse marginado» ${ }^{15}$.

${ }^{14}$ El volumen ¿Dónde estoy yo?, citado en la bibliografia, publica en 1994 textos de distintos momentos, entre ellos el artículo «;Dónde estoy?», aparecido en El Pais el 24 de febrero de 1977.

15. En un extraordinario del Suplemento «Culturas» de Diario 16 dedicado a «El futuro del teatro español» (1I de abril de 1992) se refería Buero Vallejo a la creciente devaluación de nuestros autores; Sastre decía que los escritores habían desaparecido del teatro; Nieva mencionaba la voluntad de sus alumnos de la Escuela de Arte Dramático de Madrid de «salirse» del teatro español y de sus márgenes para «teatralear» en abstracto. 
Algo hay de irreparable en el olvido de ciertos autores como tales autores ${ }^{16}$. Otros los han sustituido, algunos han mudado su rumbo o mantienen sus nombres en Encuentros y Coloquios. O en los libros y estudios. ¿En qué escenarios encontramos a Sastre, a Muñiz, a Olmo, a Rodríguez Méndez, a Martín Recuerda? ¿No merecen ya la escena? La pregunta, más que retórica, no tiene más que una contestación para quien los conozca. Pero el olvido engendra el desconocimiento. $\mathrm{Y}$ esa generación de autores de diversa edad y condición ha padecido una clara desestima por la conveniencia de borrar un incómodo recuerdo del pasado.

16 Premeditada indiferencia, cambios interesados, pérdida de la necesaria presencia... El espectáculo Haciendo memoria lucha contra todo ello con textos dramáticos escritos durante la dictadura por Espríu, Buero, Sastre, Olmo, Rodríguez Méndez, Martín Recuerda, Muñiz, Miras, Matilla y Mediero, seleccionados por José Monleón, Jerónimo López Mozo y Antonio Malonda, que lo dirigió. La lectura dramatizada de los mismos tuvo lugar el 21 de noviembre de 1997, dentro de las jornadas «Cultura y disidencia (Memoria democrática)», que se concibieron con el propósito de «sacar la memoria a la calle y hacerla vivir entre las nuevas generaciones» (Primer Acto, 271, pp. 4-6). 


\section{BIBLIOGRAFÍA}

Altares, Pedro, «Estreno de Alberti: Mientras llega la libertad», Pipirijaina, 1 (1976), pp. 43-44.

Amell, Samuel y Salvador García CASTAÑEdA (eds.), La cultura española en el posfranquismo, Madrid, Playor, 1988.

AZNAR SOLER, Manuel, «Teatro español y sociedad democrática (1975-1995)», en Veinte años de teatro y democracia en España (1975-1995), Barcelona, Cop d'idees-CITEC, 1996, pp. 9-16.

BAYÓN, Miguel, «Buero Vallejo tras La detonación: "Hay que ingeniárselas bajo las dictaduras"», Diario 16,29 de septiembre de 1977, p. 23.

Buero Vallejo, Antonio, Obra completa, I y II, edición crítica de Luis Iglesias Feijoo y de Mariano de Paco, Madrid, Espasa Calpe, 1994.

«Encuesta a los que no estrenan», Pipirijaina, 6 (1978), pp. 49-54.

EQUIPO RESEÑA, «El teatro», en Doce años de cultura española (1976-1987), Madrid, Encuentro, 1989, pp. 91-143.

FÁBREGAS, Xavier, «Crítica de Barcelona. La sangre y la ceniza», 4 (1977), pp. 64-65.

FERNÁn GómeZ, Fernando, Puro teatro y algo más, Madrid, Alba, 2002.

FERNANDEZ TORRES, Alberto, «1975-1988: Todo ha cambiado, todo sigue igual», en AA. VV., Escenarios de dos mundos, 2, Madrid, Centro de Documentación Teatral, 1988, pp. 220-233.

GARCIA LORENZO, Luciano, «El teatro español después de Franco (1976-1980)», Segismundo, 27-32 (1978-1980), pp. 271-285. Reproducido en su libro Documentos sobre el teatro español contemporáneo, Madrid, Sociedad General Española de Librería, 1981, pp. 437-449.

GORTARl, Carlos, «El Adefesio, de Rafael Alberti», Pipirijaina, 2 (1976), pp. 49-50.

Haro TeCGlen, E., «Teatro. De San Pascual a San Gil. Una víctima», El País, 5 de junio de 1980, p. 37.

LóPEZ MOZO, Jerónimo, «¿Dónde está el nuevo teatro español?», Estreno, 12.1 (1986), pp. 35-39.

López SANCHO, Lorenzo, «De San Pascual a San Gil, otro destrozo», ABC, 5 de junio de 1980 , p. 49.

MARTín ReCuERDA, José, «Escribir sobre lo que dudo», Campus (Universidad de Murcia), 41 (1990), p. 11.

MARTinez Ruiz, Florencio, «Buero Vallejo, treinta años después», $A B C, 14$ de octubre de 1979, p. 31.

MIRALLES, Alberto, «El teatro: El año de las elecciones», en AA. VV., El año literario español 1977, Madrid, Castalia, 1977, pp. 54-77.

- «iEs la guerra, más madera!», Pipirijaina, 10 (1979), pp. 12-24. 
- «La peripecia del desencanto en el teatro español: la culpa es de todos y de ninguno», Estreno, 6.2 (1980), pp. 7-10.

- «El nuevo teatro español ha muerto ¡mueran sus asesinos!», Estreno, 12.2 (1986), pp. 21-24.

- Celebración y catarsis (Leer el teatro español), Murcia, Cuadernos de Teatro, 1988.

- «Política, teatro y sociedad: temas de la última dramaturgia española», Monteagudo, 3. época, 2 (1997) (monográfico «Teatro y sociedad», coordinado por Mariano de Paco), pp. 75-92.

- «La memoria asesinada», en M. de Paco (1998), pp. 99-118.

Miralles, Alberto (ed.), Creación escénica y sociedad española, Murcia, Universidad de Murcia, Cuadernos de Teatro, 1998.

Miralles, Alberto, «Teatro histórico actual: Buero Vallejo y Alfonso Sastre», en José Romera Castillo y Francisco Gutiérrez Carbajo (eds.), Teatro histórico (1975-1998). Textos y representaciones, Madrid, Visor, 1999, pp. 129-140.

- «Alberto Miralles: rebeldía y experimentación», introducción a Alberto Miralles, Teatro escogido, Madrid, Asociación de Autores de Teatro, 1, 2004, pp. 9-36.

MIRAS, Domingo, «Sobre Riaza y la sustitución», prólogo a Luis Riaza, Antígona... jcerda! Mazurca. Epilogo, Madrid, La Avispa, 1983, pp. 5-17.

MONLEÓN, José, «El teatro», en AA. VV., El año literario español 1975, Madrid, Castalia, 1976, pp. 53-68.

MonTERO, Isaac, «Treinta años después», Informaciones, 6 de noviembre de 1979, p. 27.

Olmo, Lauro, «Auto-reflexiones», Campus (Universidad de Murcia), 40 (1990), p. 13.

PACO, Mariano de, «El teatro de Alfonso Sastre en la sociedad española», F. G. L. Boletín de la Fundación Federico Garcia Lorca, 19-20 (1996), pp.

271-283 (número coordinado por María Francisca Vilches de Frutos y Dru Dougherty).

Pérez Coterillo, Moisés, «El Búho. Estrenar en cercanías», La Calle, 23 de mayo de 1979, p. 46.

PREGo, Adolfo, «Un dramaturgo frente a la actualidad», Blanco y Negro, 10-16 de octubre de 1979 , pp. 48-49.

Rodríguez MÉndez, José María, «Mi teatro y yo», Campus (Universidad de Murcia), 28 (1988), p. 12.

Romera Castillo, José (ed.), Teatro y memoria en la segunda mitad del siglo $X X$, Madrid, Visor-UNED, 2003. 
RUIZ RAMÓN, Francisco, «Balance del teatro español en la España post-Franco», en AA. VV., España 1975-1980: Confictos y logros de la democracia, Madrid, José Porrúa, 1982, pp. 59-75.

SALVAT, Ricard, «Entrevista a Buero Vallejo», Estreno, IV, 1 (1978), pp. 15-18.

SASTRE, Alfonso, ¿Dónde estoy yo?, Hondarribia, Hiru, 1994.

SERrano, Virtudes, El teatro de Domingo Miras, Murcia, Universidad de Murcia, 1991.

Valencia, Antonio, «De San Pascual a San Gil», Hoja del Lunes de Madrid, Suplemento del 9 al 15 de junio de 1980, p. 5. 